\title{
The Application of Image Elements in the Clothing Store Display
}

\author{
Yanli Zhou ${ }^{1, a}$ \\ ${ }^{1}$ Jiangxi Institute of Clothing Technology, Jiangxi, Nanchang, 330201 \\ a54503426@qq.com
}

Keywords: Image Elements, Clothing Store Display, Brand Culture

\begin{abstract}
Clothing store display is the most important aspect of terminal clothing sales, in the moment "Terminal Winning" marketing era, how to build a science and attract the attention of consumers clothing store environment is an important means of corporate marketing. In today image element is the dominant element and it has incomparable advantages because of its visual image elements, brought by the spread of the appeal, in terms of the desire to inspire customers to buy. This paper argues that in the clothing store display image elements in use is not only a marketing tool, it is the propaganda of brand value and brand culture and it is the development direction of the future show.
\end{abstract}

\section{Introduction}

With the "Book Age", the image has become accepted in today's society, the spread of major media news letter mode. Store display image elements generally static, dynamic form to attract the attention of consumers, so as to promote sales. Clothing on display in the store not only sale terminals, it is an important carrier of commercial competition and dissemination of information, good clothing display performance is an important means of corporate brand image, it can show the brand concept, highlighting the brand culture and meaning, reflect the brand alone some personality, characteristics, deepen consumer understanding of the brand, enhance the added value of goods. The introduction of the concept of image elements in the clothing on display in order to image the unique visual impact, to create a new clothing store display effect, this article from the image elements on consumer awareness, the image on the display element in creating an atmosphere and corporate culture create aspects to carry out exposition.

\section{The Concept of Image}

The concept of the image can be divided into two narrow and broad. Images in the narrow sense, namely photography referred to herein as: refers to feelings of light through optical devices, electronic devices, digital devices, is projected shape of the subject and the light reflected by the light caused by a chemical reaction, electronic or electromagnetic pulse changes in the image obtained and recorded, stored in the medium, if necessary, and then to copy or duplicate it presented "image object", which includes movie video and television images photographed image stationary, moving, multi-dimensional network image etc. [1]. Images are broadly includes photographic images, scanned images and digital images of three.

\section{The Effect of Store Display}

With the improvement of people's living standards, people have gradually put clothes shopping process as a kind of visual enjoyment and aesthetic experience. Therefore, the requirements at the time of image display clothing display design and conduct, should pay more attention to explore the beauty and create beauty, make clothing more prominent display of aesthetic function to attracted the eyes of the customer. In the consumer-driven market economy environment, the store has become a space of consumers everyday life, even to the store shopping for consumers to pursue a way of life. Marketplace is not only the most remote sales channels, the closest place to the consumer, is one of the carrier business competition, and information dissemination. 
Store terminal into "soft interrupt" and "hard end" two categories, hard terminal, mainly indoor exhibition and display products, such as lighting, POP advertising; soft terminal refers to the regular activities, changes in people, such as promoters, shopping guide member.The concept of the origin of the domestic apparel in the early 1990s until the present, the domestic apparel store model are the following [2]:

The Department Store. Also known as the "shop in shop", refers to the store in the form of a department store in general, middle-income families over the main place to buy textile products. Their common features are: noble quality, stylish, elegant, personalized focus on branding image and high value-added; focus on brand visual communication design, service, targeted.

Monopoly Shop. Professional and branded manufacturers showcase products and services, targeted at mid-range consumer level. Product quality, high quality, serialization and extent of diversification, brand standards, comfortable shopping environment, stable foster brand loyalty, providing comprehensive services.

The Big Selling Games, Super City. Hypermarkets, supermarkets generally located near a large residential area, locate low, the target consumer group is low-income families. Its main features are: low prices, the image of the traditional, emphasizing practical rationality; low price, quantity for market entry point, not too much design, marketing investment.

Store display store channel by means planning, display, lighting, POP posters, music, props, store atmosphere and a series of elements of products were carefully designed to create a textile store atmosphere demands, thereby promoting product sales, enhance brand image. As an emerging interdisciplinary, store display windows work just furnished, with color, but rather a complex set of visual arts, marketing and ergonomics multidisciplinary knowledge.

\section{The Cognitive Affect of Image Elements on the Consumer in the Clothing Display}

Psychological research shows that all of the information we receive $83 \%$ of which comes from the visual, $11 \%$ comes from hearing, and 6\%, respectively, from the smell, touch and taste [3]. Visual merchandising for consumer sensibility through favorite information so that consumers feel good merchandise to obtain a pleasant shopping experience. When consumers walk into an array of stores, for a time of only 7 seconds of clothing, in such a short period of time to attract the attention of consumers, the image becomes more important. Image elements in the clothing store display we can roughly be divided into static images and motion pictures. Currently, more static image elements in the form of clothing store display, the contents mainly store POP and interactive video spokesperson and brand products.

POP Marketplace. Compare point of purchase "referred POP advertising, specifically refers to the purchase of the stores are in the process of persuading customers direct effect of advertising in the clothing display the POP advertising, design more flexible and can be converted at any time on the basis of furnishing needs, content brief, specific, focused energy, people can read POP advertising is also within 1.15 seconds, that is, for a second can lead to interest-based advertising, the customer only a maximum of 15 seconds reading time. Therefore, POP advertising to be in the store arouse the attention of customers in a short time, the contents of control in less than 3 lines 20 characters, such stores are often seen "hot commodity this week", "best-selling products this season" and POP advertising, through positive affirmation of the customer decision-making or implied, to promote the sale of goods.

The Interactive Image of Product and Brand Ambassador. Clothing display includes the poster, book, etc. These images through the details of the product features, highlighting the fine selection of merchandise and manufacturing processes, the image of light, shadow, color can bring people to the visual, emotional impact. Meanwhile brand image and product spokesperson interaction, can play a celebrity, so that the transfer of customer goodwill ambassador to the attitude of the products and brands, thereby strengthening the brand, fashion guide consumption. Clothing stores in the windows, booth color and design, will be presented with the image elements in harmony, and you can set the focus by spotlights, backlight and other arrangements, the formation of the visual center to attract the attention of consumers. 
With the advances in imaging technology elements in addition to the clothing store display static display, with LED, big screen TV as the carrier of a dynamic image gradually being widely used, motion pictures multi-sensory stimulation to strengthen consumer awareness. These images are the elements in the clothing store in the use of fully meet the strong consumer demand for visual maximize highlights the sense of presence and a sense of the value of goods, the impact of changing consumer perception. Image elements not only full visual impact, and it can be more quick to construct consumer image among consumers than the physical brain, the fastest way to help consumers understand the brand style, culture and product characteristics.

\section{The Impact of Image Element on Clothing Display Atmosphere}

Display means that the atmosphere through a variety of sensory, perceptual change around color, lighting, music, temperature, odor and other factors, consumer perception and emotional response to their environment, in order to promote sales of products for the ultimate goal [4].

In creating a clothing store display in the atmosphere, the dominant color, usually dominated corporate color tone to decorate the scene, which together with paintings or photographs coordination between primary colors and secondary colors, the selected image should be consistent brand identity, for example the US Masters - Bonwe as a definition for personalized fashion leisure brand, with blue background and white text on the first door and window color, window and in-store posters using Jay, Lin Chi-ling endorsement image, creating a lively, personalized younger image, can resonate with younger age groups.

Because of the diversity of the motion picture stimuli, in creating the atmosphere of the scene to be used more. In international brands LV store window, the display of a large screen, playing a shirt making flow chart on the screen, with the surrounding environment clean and elegant shirt echoes die, full of creative ideas to fill the gap production, not only can cause intense curiosity of consumers, but also publicize its brand has always insisted on the idea of sophisticated technology. At the same time the TV screen can also play new introduction, product discounts, corporate profiles and other information, through dynamic picture and sound, effective in attracting the attention of pedestrians.

With the change in people's consumption concept, it is not simply the value when shopping for the use of the function and value of goods, and gradually shift to additional psychological value of the goods, pay more attention to the psychological feeling when shopping. Monotonous stores through the application of image elements, the traditional buying process of sublimation for an interactive two-way propagation leisure experience, a different atmosphere to bring customers a different shopping experience, customers have reduced the fatigue in the consumption process.

\section{Dissemination of Images Elements of Corporate Culture}

Corporate culture is a long-term production and management practice in the formation is an effective means to solve the contradiction between producers and consumers. The impact of corporate culture on consumers primarily through media communication and sales terminals to achieve, and the use of sale terminals in favor of corporate image elements in cultural norms, widely disseminated [5].

Corporate culture is to meet rising consumer demand for psychological, with the improvement of living standards, to meet their physical needs on the basis of the material, gradually shift the demand for enjoyment and development. Customers are bound to these aspirations through a variety of products and services, features, brand, cultural connotation to achieve. In the product homogeneity serious today, the corporate culture of propaganda to help meet consumer demand for personalized and diversification, brand logo, colors, graphics and other visual elements are the specific carrier, for example Metersbonwe's brand ME \& CITY, Metersbonwe focus on young consumers, when they age and then into the workplace, consumer habits and preferences will change, in order to meet the individual needs of this population, Metersbonwe and then launch the ME \& CITY brand, aimed at 18-35-year-old white-collar city, that "urban fashion without borders" 
brand advocates, is biased in favor of the campus-style brand Metersbonwe complementary extension is further refined to consumers and respected. ME \& CITY store furnishings like to use more modern girl as workplace gentleman, fashion accessories and other graphic posters, ME \& CITY Metersbonwe background and knowledge, corporate culture video presentation, use of these imaging elements and helps Metersbonwe ME \& CITY recognition and convergence of consumer groups, the consolidation and continuation of consumer groups.

Imaging element is the performance of the corporate brand image is an important tool that can show the brand concept, highlighting the cultural connotation of the brand, reflecting the brand's unique personality, character, deepen consumer understanding of the brand; enhance the value of goods, obtain higher profits, win the favor of consumers.

\section{Conclusions}

In the era of pictures today, we should see that for the integrated use of image elements, in particular the establishment of cultural marketing system image is still in its infancy stage, still images, moving images, interactive holographic technology, network and other elements of the virtual image and corporate culture the system application and interaction remains to be studied. However, we believe that as technology advances, image elements will be presented by the static to dynamic, from flat to three-dimensional, there are real to virtual conversion, and ultimately for the consumer's inner needs and brand value concept of service.

\section{References}

[1] Sue Jiao: Journal of Xinyang Normal University, Vol. 5(2003) No 23, p.101-103

[2] Tong Han: Productivity Research, Vol. 6 (2011) No 20, p.74-76

[3] Lihua Xu: Culture Studies, Vol. 3 (2002) No 33, p.11-14

[4] Li Wu: Guangxi Normal University, Vol. 3 (2007) No33, p.121-124

[5] Maozhong Ye: Productivity Research, Vol. 9 (2004) No 33, p.11-14 